Original Research Paper

\title{
Encouraging High School Student Interest in Computing Studies in GCC: UAE Case Study
}

\author{
Manar Abu Talib \\ Department of Computer Science, University of Sharjah, P.O. Box: 27272, Sharjah, United Arab Emirates
}

\author{
Article history \\ Received: 05-07-2015 \\ Revised: 5-09-2015 \\ Accepted: 30-10-2015 \\ E-mail: mtalib@sharjah.ac.ae
}

\begin{abstract}
Computational studies have an impact on fields like biology, chemistry, linguistics, psychology, economics and statistics. They develop skills such as problem solving and systems design and improve understanding about the power and limits of human and machine intelligence. The Global Science Forum emphasizes on collecting accurate and unbiased information as important strategy to increase the attractiveness of Science and Technology studies and careers. Such information should not only be shared with students but also to the education community and parents. To the best of our knowledge, there has been no research into student recruitment for computing studies in the GCC. To study recruitment in this research paper we focused on three groups: Parents, high school teachers and students. Sustainable communication and efforts with these groups will certainly be central to encouraging high school student interest in computing studies in the GCC. This study suggests a list of actions that may increase the enrollment in the fields of computing and represents a leading effort for other countries in the GCC specifically and the Arab world in general.
\end{abstract}

Keywords: Computer Science, Student Recruitment, High School, Teachers, Students, Parents

\section{Introduction}

"Computer Science is no more about computers than astronomy is about telescopes" Dijkstra said. According to the Computing at School Working Group, "Computer Science is deeply concerned with how computers and computer systems work and how they are designed and programmed. Pupils studying computing gain insight into computational systems of all kinds, whether or not they include computers. Computational thinking influences fields such as biology, chemistry, linguistics, psychology, economics and statistics. It allows us to solve problems, design systems and understand the power and limits of human and machine intelligence. It is a skill that empowers and that all pupils should be aware of and have some competence in. Furthermore, pupils who can think computationally are better able to conceptualise and understand computer-based technology and so are better equipped to function in modern society" (CSWG, 2014).

Moreover, in the same CSWG study endorsed by the Chartered Institute for IT (BCS), Microsoft,
Google and Intellect, the authors state that "Computer Science is a practical subject, where invention and resourcefulness are encouraged. Pupils are expected to apply the academic principles they have learned to the understanding of real-world systems and to the creation of purposeful artifacts. This combination of principles, practice and invention makes it an extraordinarily useful and an intensely creative subject, suffused with excitement, both visceral ("it works!") and intellectual ("that is so beautiful")."

Based on worldwide computer science enrollment data over the past three decades, a majority of academics believe that enrollment numbers follow a cyclical pattern. Recent reports show that graduate and undergraduate enrollment has grown for a fifth straight year in the USA, (Zweben, 2013; Abu Talib and Elnagar, 2014). The numbers here in the UAE are no exception to this observation. Figure 1 shows the number of students enrolled in the department in the last five years. According to Abu Talib (Abu Talib and Elnagar, 2014; Abu Talib et al., 2012; Abu Talib and El Barachi, 2011), enrollment of students majoring in the computing field is still an issue for many universities all over the world. 


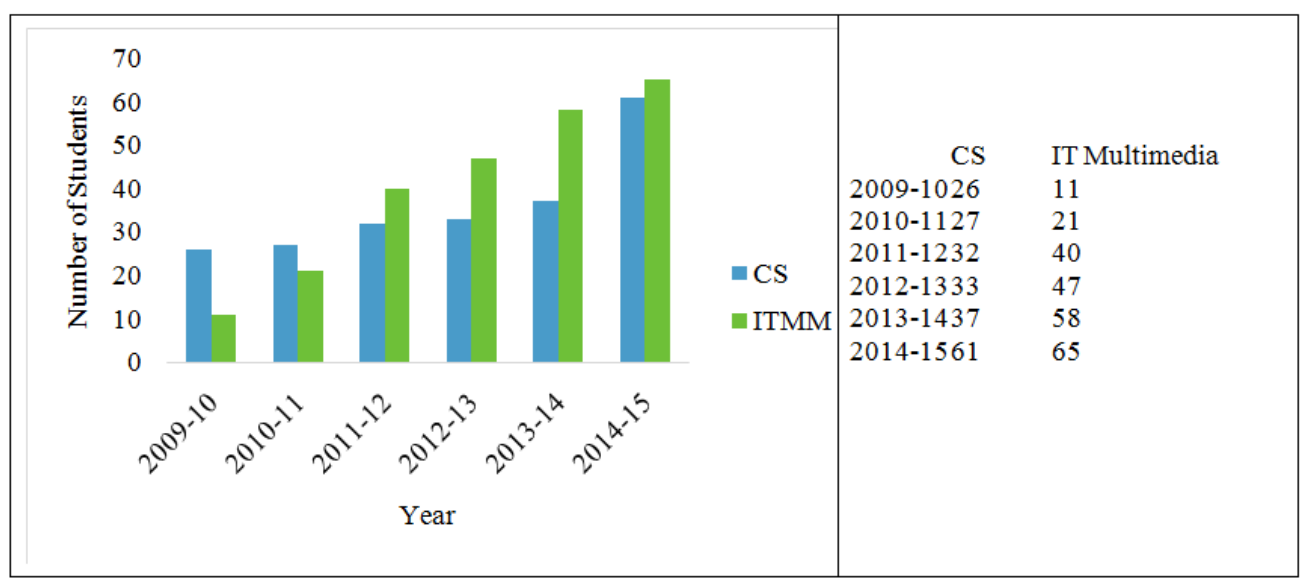

Fig. 1. Student enrollment in computer science

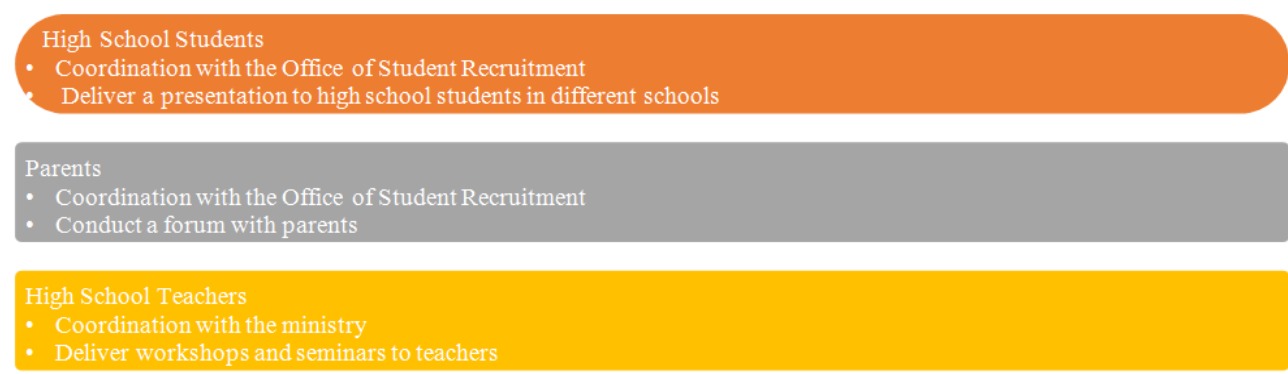

Fig. 2. Computer science awareness campaign for three groups

We have noticed that a significant percentage of newly admitted students may enroll in an academic program for reasons that do not accord with their genuine interest. For example, some follow parental advice while others go with the general flow. There is little research done to study the challenges, the reasons and the opportunities that may affect the enrollment in the fields of computing in the Arab World. For the purpose of studying recruitment, this research paper focuses on three groups: Parents, high school teachers and students. The remaining of this paper is organized as follows: the related work is reviewed in section 2. Section 3 outlines the research design (Fig. 2). The results are discussed in section 4 and future directions are presented in section 5 .

\section{Literature Review}

According to the Global Science Forum (OECD, 2008), "An understanding of science and technology is necessary not only for those whose career depends on it directly, but also for any citizen who wishes to make informed choices about many controversial issues being debated today. Recently, a number of countries have expressed the fear that interest in Science and Technology is declining, even as demand for Science and Technology graduates grows."
Many approaches and strategies for increasing enrollment in computing studies have been proposed and discussed, such as:

- Computer science classes for $\mathrm{K}-12$ at an early stage (CSTA, 2003). This proposal by the Computer Science Teachers Association (CSTA) is one of the best initiatives that targets increasing awareness and knowledge among K-12 students (CSTA, 2003; 2005)

- A computer science curriculum for schools (CSWG, 2014). The CSWG maintains that computer science and Information Technology (IT) are disciplines within computing that, like mathematics or history, everyone should study while in school

- Presenting computer science concepts to high school students (Bell et al., 2014)

- Advising guidance counsellors, who themselves need more knowledge about the computing field and its opportunities (Saunders and Hunsinger, 2008)

- Focusing high school teachers on attracting diverse students to computer science and engineering (Cohoon et al., 2011). The influence of a single teacher can have a life-long impact on a student's interests (Goode, 2007) 
- Conduct presentations and activities totnspire undergraduates to pursue a major in computer science or IT (Frieze and Treat, 2006; Roberts et al., 2003)

- Other researchers have addressed the problem from a different point of view, such as designing computing courses to be taken as electives (Guzdial and Forte, 2005)

- Motivating female students to major in computer science (Fisher et al., 1997; Force, 2008)

In the Arab world, there are several initiatives, competitions and programs that encourage innovation by computer science students and that offer them many opportunities. For example, the Arab World Association of Young Scientists (ArabWAYS) is the first platform for young scientists and researchers in the Arab World. One of their main objectives is to network young Arab scientists together with other scientists worldwide and with the international community (ArabWAYS, 2013). Another example is the Arab Computer Society (ACS), which facilitates cooperation among computer science scholars, researchers, academics and professionals working in the Arab world as well as researchers worldwide who are interested in the IT industry/profession in the Arab World (ACS, 2013). However, to the best of our knowledge there are few recent studies that address student enrollment or discuss the enrollment challenges in the Gulf Cooperation Council (GCC) specifically and in the Arab World in general. For instance, El-Sanabary collected reports from many countries on educational developments between 1950 and 1980 (El-Sanabary, 1992). One of these included a 1981 survey of computer science education in universities in several Arab countries including Iraq, Kuwait, Qatar, Saudi Arabia and the United Arab Emirates. The goal was to evaluate the current stage of development in computer engineering, computer science and computer-based management information systems (El-Sanabary, 1992). Another publication by UNESCO addressed science, technology and education but there was no clear indication of the numbers of students enrolled in computing fields in the Arab World (UNESCO, 2003). Our review reveals a gap in the literature regarding this topic. In this study, therefore, we provide a roadmap for the GCC and the Arab World in the hope of promoting enrollment in computer science and related fields.

\section{Research Design}

As discussed in the previous section, student enrollment in computing fields continues to be a challenge for many universities in the world. Academics and researchers have proposed many different approaches and strategies to increase enrollment in such fields. In this study, we focus on three demographic groups to survey and influence: parents, high school teachers and students.

In the UAE, students choose their major once they have passed their final high school exams. So, in an effort to recruit more students into our computer science department, we began coordinating with the Office of Student Recruitment starting in September 2013. We worked closely with the director and held three meetings to finalize the presentation to be made to high school students. The presentation was created and carefully reviewed in consultation with Computer Science Department faculty members. The following issues were addressed:

- What a computer science professional looks like, e.g., appearance, gender, work habits, emotional state, sociability, intelligence, income, etc.

- Reasons for choosing information technology or computer science as a career

- The ubiquitous nature of computers

- Careers in computer science

- Potential employers of Computer Science/IT graduates

- The top 10 reasons to major in computing

- Misconceptions about computer science

- Future trends: Job growth in science and technology; comparison of current supply with future demand for holders of undergraduate, graduate and postgraduate degrees; contribution of Computer Science/IT to overall growth in science and engineering occupations

- What our Department offers

- Computer science courses

- Computer science clubs

- Two videos: Our robot and our Department's people

As a result of these meetings, the Student Recruitment Office team coordinated with five high schools (251 students in 2013 and more than 300 in 2014 ) to give a general presentation about the University of Sharjah (UOS), followed by a presentation on the Computer Science Department. UOS now holds an annual open house for all high schools, where students are free to ask about the various majors to follow when admitted to the university (Abu Talib and Elnagar, 2014). In the same week, there is an open house for families, including a forum where parents can have their questions and concerns addressed (Abu Talib and Elnagar, 2015). In addition, in 2015 the Google CS4HS fund provided great assistance in delivering two workshops and two seminars for UAE high school teachers. Table 1 summarizes the Computer Science Department presentations, "Hour of Code," cyber security seminars and MIT Inventor workshops. 
Table 1. Student recruitment plan

\begin{tabular}{|c|c|c|}
\hline Date & School name & \# of students \\
\hline \multirow[t]{3}{*}{$11 / 2013$} & CS presentations to High Schools (BOYS) & \\
\hline & International School of Creative Science & 45 \\
\hline & Sharjah American International School & 65 \\
\hline $11 / 2014$ & Dubai International School & 150 \\
\hline \multirow[t]{4}{*}{$11 / 2013$} & CS presentations to High Schools (GIRLS) & \\
\hline & International School of Creative Science & 60 \\
\hline & Sharjah American International School & 47 \\
\hline & Al Kamal American School & 34 \\
\hline $11 / 2014$ & Dubai International School & 150 \\
\hline $5 / 2014$ & Open House for all schools & 8000 \\
\hline $12 / 2014$ & Open House for all schools & 10,000 \\
\hline "Hour of Code"* & Grades 1-5 (Mix) & \\
\hline $12 / 2013$ & Australian International School & 515 \\
\hline $12 / 2014$ & Australian International School & 750 \\
\hline \multirow[t]{2}{*}{$12 / 2014$} & "Introduction to IT" course & 300 \\
\hline & Programming courses & 350 \\
\hline Date & Open Day for families & \# of parents \\
\hline $5 / 2014$ & Forum with parents & 100 \\
\hline $12 / 2014$ & Forum with parents & 200 \\
\hline Date & High School Teachers & \# of teachers \\
\hline $2 / 2015$ & IT Teachers & 49 \\
\hline $4 / 2015$ & Math Teachers & 61 \\
\hline
\end{tabular}

* in the second week of December, Code.org conducted a massive campaign to get 10 million students of all ages to participate in the Hour of Code as part of the annual Computer Science Education Week (CSEdWeek). CSEdWeek is a celebration to inspire awareness in the field and show that anyone can learn the basics of computer science (HCPG, 2014)

\section{Results}

Findings from the survey data analysis revealed more commonalities than differences among parents, high school students and teachers. The results are explained in more detail below.

\section{High School Presentation Results}

Table 2 presents the results of a survey showing student views of Computer Science before seeing the presentation. It consisted of one matrix question to check more than one answer (Abu Talib and Elnagar, 2014).

Table 2 shows clearly that most students (male and female) claim not to know much about computer science. The second highest option selected by both male and female students was "technician job." This indicates a common misconception that many students have about computer science, which was discussed in the presentation. The other misconception is that computer science is a male-dominated field, which was not reflected in the survey results here. A higher percentage of students described computer science as "hard" rather than "easy." A good number of students realized that it is an important field of study, which means it is needed in the market. Finally, the percentage for the "fun" option was higher for male students than the "boring" option, whereas the opposite was true for female students (Abu Talib and Elnagar, 2014).
Table 3 presents the survey results after the presentation. Around 42 male students (62\%) reported that the presentation was Excellent/Very Good. The more interesting result is that $82 \%$ agreed they learned "some interesting and new stuff" about computer science and ITs. More than half (62\%) agreed that computer science is interesting and needed and that everyone should have some background in it (Abu Talib and Elnagar, 2014).

On the other hand, 67 female students $(78 \%)$ reported the presentation was Excellent/Very Good. 91\% agreed that they learned "some interesting and new stuff" about computer science and IT. However, while close to half of female students $(46.5 \%)$ thought that CS is interesting and needed and everyone should have some background in it, $51.16 \%$ reported that while CS is needed, they were not interested.

Overall, both male and female students actively interacted during the presentation. We informed them that we were not lecturing but sharing ideas and listening to them too. Female students were more interested in talking to us after the presentation and asking more questions. Some of the comments we received in the survey include: "I am now interested in computing field even more", "Great presentation," "Very nice and entertaining presentation," "Sadly, that is not my choice,"“So funny, I laughed." 
Table 2. Survey results prior to the presentation to high school students (Abu Talib and Elnagar, 2015)

\begin{tabular}{|c|c|c|}
\hline & Male students & Female students \\
\hline Number of participants & 66 & 86 \\
\hline I didn't know much about computer science & $47 \%$ & $46 \%$ \\
\hline I know a lot about computer science & $12 \%$ & $4 \%$ \\
\hline Computer Science is a technician job & $23 \%$ & $37 \%$ \\
\hline Boring & $15 \%$ & $22 \%$ \\
\hline Fun & $21 \%$ & $13 \%$ \\
\hline Easy & $8 \%$ & $1 \%$ \\
\hline Hard & $14 \%$ & $14 \%$ \\
\hline For males and females & $17 \%$ & $20 \%$ \\
\hline For males & $2 \%$ & $0 \%$ \\
\hline Important & $23 \%$ & $15 \%$ \\
\hline
\end{tabular}

Table 3. Survey results after the presentation to high school students

\begin{tabular}{lrr}
\hline Survey question & Male (\%) & Female (\%) \\
\hline What do you think of today's presentation? & 10.60 & 5.80 \\
o Ok & 25.80 & 16.30 \\
o Good & 39.40 & 43.00 \\
o Very Good & 24.20 & 34.90 \\
o Excellent & 81.80 & 90.70 \\
Did you learn some interesting and new stuff about Computer Science/IT as a major? & 18.20 \\
o Yes & 62.10 & 9.30 \\
o No & 46.50 \\
After today's presentation, do you find Computer Science is: & 37.90 \\
o Interesting and needed. Everyone has to have some background in Computer Science background & 51.20 \\
o Needed but I am not interested & 0.00 \\
\hline Not needed and I am not interested & 2.30 \\
\hline
\end{tabular}

Table 4. Parent survey results

\begin{tabular}{lc}
\hline Survey question & Parents (\%) \\
\hline What does a Computer Science professional look like? & \\
Wearing glasses? & \\
Yes & 40.30 \\
No & 14.90 \\
Maybe & 44.80 \\
Male, Female, Either? & \\
Male & 20.90 \\
Female & 10.40 \\
Either & 68.70 \\
Sitting all the time in front of a PC? & \\
Yes & 44.80 \\
No & 40.30 \\
Maybe & 14.90 \\
Working under pressure? & \\
Yes & 44.80 \\
No & 23.90 \\
Maybe & 31.30 \\
Connected to the world? & \\
Yes & 73.10 \\
No & 7.50 \\
Maybe & 19.40 \\
Smart and Nerdy? & \\
Yes & 52.20 \\
No & 7.50 \\
Maybe & 40.30 \\
Yes & \\
No & 22.40 \\
Maybe & 19.40 \\
Vomputer Science is: & 58.20 \\
Important & 74.60 \\
OK & 23.90 \\
\hline & 1.50 \\
\hline
\end{tabular}

\section{Parents}

Table 4 presents the views of parents about computer science professionals before their questions and concerns were addressed at the University Open House. 67 parents answered the survey (Abu Talib and Elnagar, 2015).

The survey results reveal a positive image of computer science professionals among parents, although they were reluctant to advise their children to major in it. $69 \%$ of parents saw the field as being for both males and females. More than $70 \%$ of parents agreed that computer science is important and that professionals in this field are well connected to the world. More than 50\% agreed that professionals are "smart" and "make a lot of money." On the other hand, more than 50\% said professionals in the field work under pressure and spend most of their time in front of the PC. Despite the positive results of the survey, it reflects a lack of interest in Computer Science/IT as an attractive major among many parents. Talks with several parents at the UOS Open House revealed many of them were more interested in other majors. This may reflect the low awareness they have about computing fields. More effort needs to be made to target students' parents.

\section{High School Teachers}

We were able to organize two workshops on MIT Inventor App for 100 high school IT and Math teachers invited by The Sharjah Education Council. The first 
workshop was on February 17 and the second on April 28, 2015. We also gave a seminar entitled "Cyber Safety in the Information Age". Fifteen faculty members and staff were involved in organizing and running the workshops and seminar. Feedback from the high school teachers included such comments as: "Amazing workshop and very organized one," "After 13 years, the teachers were involved again with University of Sharjah activities," "Caring team, not like other workshops the teachers attend and they feel it is a duty to be done," "We want to have a panel discussion about IT field and the challenges faced in high schools," "Get us involved in choosing the topic for the next workshop." It is clear from the comments that they have many challenges we need to overcome. These challenges were exactly the same as described by the CSTA (CSTA, 2005):

- Computer science teachers feel isolated within their schools and districts

- Administrators do not understand that computing is a scientific discipline just like physics and biology

- There is no consistency in computer science curriculum requirements from state-to-state, districtto-district or even, in some cases, school-to-school

- Computer science teachers do not receive the professional development they need to keep their teaching and technical skills current

- There is a disconnect between K-12 computer science educators and their college/university colleagues

- Administrators, legislators and congressional committees do not understand the link between supporting K-12 computer science education and economic/workplace issues (the national discourse example)

- Students and their parents do not understand the incredible scope of educational and career opportunities that having computing skills provides
- Students want to be part of a discipline that is solving real problems and they do not understand that computing is at the root of all of the new sciences

- Student schedules are so jam-packed that they do not have time to take electives

Table 5 and Fig. 3 and 4 summarizes the teachers' overall impression of the workshops and seminars.

The high school teachers who attended the workshops became ambassadors for our Computer Science Department and will continue to be updated about the latest Computer Science news to keep them in the loop. They will be our point of communication with students. The University website for the CS4HS project iswww.sharjah.ac.ae/cs4hs. Photos of the events were posted by the Google Developer Group (GDG) Sharjah at https://plus.google.com/b/114853679727880166293/pho tos/114853679727880166293/albums/611782689125689 9089.

The outcomes of the surveys and events gave us a heightened responsibility to make the events sustainable (offered annually or biannually). The Google CS4HS award was a great source of help in building a strong bridge with high schools and achieving higher enrollment in the Computer Science Department. Future projects will be based on the feedback obtained from the high school teachers. It will be in two parts:

- A panel discussion about challenges \& recommendations regarding Computer Science/IT in high schools

- A hands-on workshop on either robotics or mobile applications, depending on the preference of the high school teachers

In summary, we conducted around six presentations to 500 high school students, couple of events to 1260 high school students, open house to 18,000 high school students, two workshops to 110 high school teachers (Math and IT) and two forums to 300 parents.

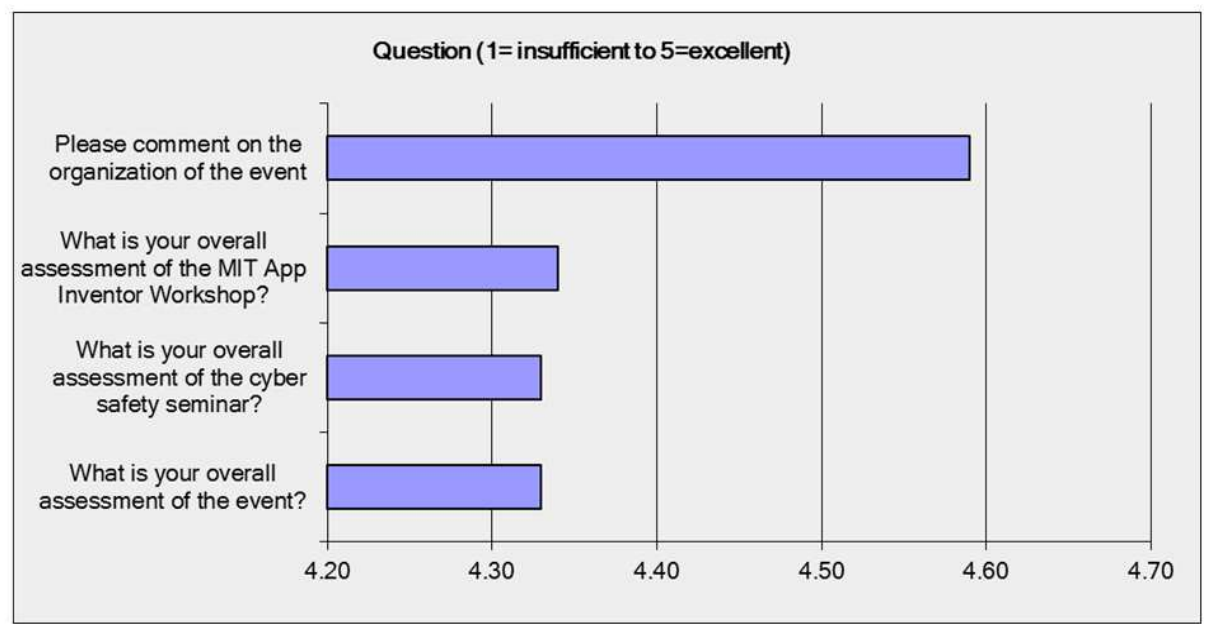

Fig. 3. Feedback from IT teachers 


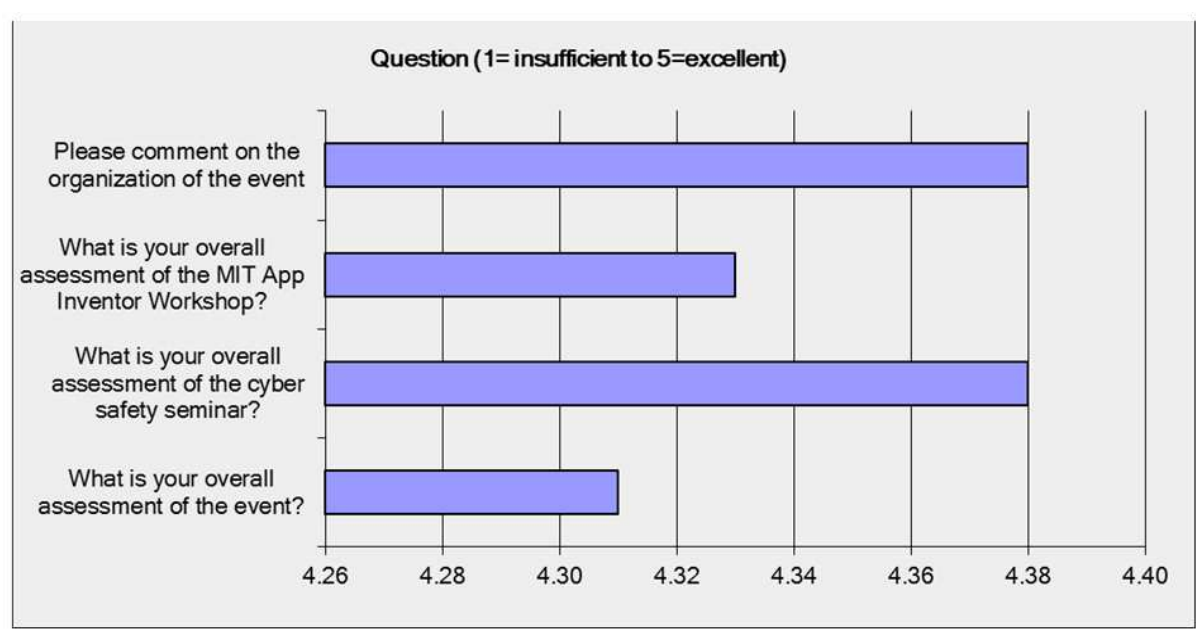

Fig. 4. Feedback from math teachers

Table 5. High school teacher survey results

\begin{tabular}{|c|c|c|}
\hline Survey question & IT teachers $(\%)$ & Math teachers $(\%)$ \\
\hline \multicolumn{3}{|c|}{$\begin{array}{l}\text { Knowledge and information gained from participation at } \\
\text { this event met your expectations? }\end{array}$} \\
\hline Yes & 75.80 & 82.90 \\
\hline No & 3.00 & 5.70 \\
\hline Somewhat & 21.20 & 11.40 \\
\hline \multicolumn{3}{|c|}{$\begin{array}{l}\text { Knowledge and information gained from participation at this } \\
\text { event will be useful/applicable in my work? }\end{array}$} \\
\hline Definitely & 56.30 & 50.00 \\
\hline Mostly & 31.30 & 36.10 \\
\hline Somewhat & 12.50 & 13.90 \\
\hline Not at all & 0.00 & 0.00 \\
\hline
\end{tabular}

\section{Discussion}

Future direction will include two main objectives:

- Collecting feedback from high school IT teachers about why they believe high school students do not choose a computer science major when entering university and what recommendations they have to remedy the situation. Based on this feedback, the University can approach the Ministry of Education to discuss ways and means to empower computer science education in high schools in the region.

- Developing a strong bridge to high schools by offering hands-on workshops either annually or biannually. Also, keeping high school teachers up to date with the latest technologies and applications.

We therefore recommend the actions listed below as a follow-up:

- Conduct a survey study for each activity and study the growth of enrollment in computing fields at UOS in particular and in the UAE in general

- Communicate with the Ministry of Education about the IT curriculum in the high schools and how to make improvements
- Organize a Computer Science Day for high school students and their families that would include presentations, booths, alumni speakers and live demos. Parents are one of the main influences on a student's choice of a major and it would be a beneficial for faculty members to have the opportunity to address them face-to-face, to respond to their questions and concerns

- Develop promotional materials such as brochures, bulletin boards, websites, social media, banners, etc

A road map to achieve the above action items is summarized as follows (OECD, 2008):

- Governments may require better understanding of enrollment in fields related to science and technology. Analysis here should be followed by efforts to estimate the future demand for science and technology graduates at all levels.

- Government should provide resources to support the dissemination of accurate information to increase the attractiveness of studies and careers in science and technology. This information should also be communicated to students, the education community and parents 
- Curricula should be redesigned to provide more attractive and relevant content, especially in secondary-level education. Teaching should also be more innovative, relying less on information retention

- Governments and relevant institutions should provide adequate resources for teacher training and classroom activities. Rewards should be provided to teachers who make the effort to upgrade their skills and knowledge or who invest their time in science and technology communication

- The learning context should be modified to make it more attractive to female students and mentoring projects should be encouraged to support women and minority students undertaking careers in science and technology. This will not be a big challenge in the Arab world as more and more young women are choosing these fields

\section{Conclusion and Future Research}

Computer Science is "a discipline that seeks to understand and explore the world around us, both natural and artificial, in computational terms" (CSWG, 2014). Although there has been an increase in enrollment in computing fields recently, more effort is needed to attract students to these fields, as the labor demand is also growing. This research paper focused on three fundamental demographic groups: Parents, high school students and teachers. The survey results indicate a promising future if and only if the University can establish a meaningful and solid bridge to these three groups. Sustainable communication can be established with the help of the student recruitment office, the concerned departments and the ministry of education. Such sustainable communication and efforts with these groups will certainly be central to encouraging high school student interest in computing studies in the GCC. This study suggests a list of actions that may increase the enrollment in the fields of computing and represents a leading effort for other countries in the GCC specifically, and the Arab world in general.

\section{Acknowledgment}

The author extends sincere thanks to Google CS4HS for funding the workshops and seminars delivered to high school teachers. She is also grateful to the Office of Student Recruitment at University of Sharjah, as well as the Sharjah Education Council.

\section{References}

Abu Talib, M. and A. Elnagar, 2014. A new computer science student recruitment strategy University of Sharjah (UOS) case study. J. Comput. Sci., 11: 145-152.
Abu Talib, M. and A. Elnagar, 2015. Inspiring students to empower computer science. Proceedings of the 7th International Forum on Engineering Education Quality Assurance in Engineering Education, Mar. 17-19, University of Sharjah, United Arab Emirates.

Abu Talib, M. and M. El Barachi, 2011. Revitalizing the IT College: A case study. Proceedings of the 2nd Manipal Conference on Technology Management (MCTM '2011), pp: 1-5.

Abu Talib, M., M. El Barachi and O. Ormandjieva, 2012. An innovative marketing strategy to promote our college of IT: Zayed University Case Study. Issues Informing Sci. Inf. Technol., 9: 161-175.

ACS, 2014. Arab computer society. ACS.

ArabWAYS, 2014. Arab world association of young scientists. ArabWAYS.

Bell, T., C. Duncan, S. Jarmen and H. Newton, 2014. Presenting computer science concepts to high school students. Olympiads Inf., 8: 3-19.

Cohoon, J., J.M. Cohoon and M.L. Soffa, 2011. Focusing high school teachers on attracting diverse students to computer science and engineering. Proceedings of the 41 st ASEE/IEEE Frontiers in Education Conference, Oct. 12-15, IEEE. pp: F2H1-F2H-5. DOI: 10.1109/FIE.2011.6143054

CSTA, 2003. A model curriculum for K--12 computer science: Final report of the ACM K--12 task force curriculum committee. USA ACM.

CSTA, 2005. The New Educational Imperative: Improving High School Computer Science Education. USA: ACM.

CSWG, 2014. Computer science: A curriculum for schools, computing at school working group. UK.

El-Sanabary, N., 1992. Education in the Arab Gulf States and the Arab World: An Annotated Bibliographic Guide. 1st Edn., Taylor and Francis, ISBN-10: 0824082494, pp; 572.

Fisher, A., J. Margolis and F. Miller, 1997. Undergraduate women in computer science: Experience, motivation and culture. Proceedings of the 28th SIGCSE Technical Symposium on Computer Science Education, Feb. 27-Mar. 01, IEEE Xplore Press, New York, pp: 106-110. DOI: $10.1145 / 268084.268127$

Force, I.D., 2008. IST strategic plan: Building the brand through partnership networks for excellence. University Park.

Frieze, C. and E. Treat, 2006. Diversifying the Images of computer science: Carnegie Mellon students take on the challenge!. Proceedings of the Conference Women in Engineering Programs and Advocates Network (WEP' 06), USA.

Goode, J., 2007. If you build teachers, will students come? The role of teachers in broading computer science learning for urabm youth. J. Educ. Comput. Res., 36: 65-88. 
Guzdial, M. and A. Forte, 2005. Design process for a non-majors computing course. Proceedings of the 36th Technical Symposium on Computer Science Education (CSE' 05), St. Louis, Missouri, USA.

HCPG, 2014. Computer science education week. Hour Code Participation Guide.

OECD, 2008. Encouraging student interest in science and technology studies. OECD.

Roberts, E.S., M. Kassianidou and L. Irani, 2003. Encouraging women in computer science. Bulletin Women Comput., 34: 84-88.

DOI: $10.1145 / 543812.543837$
Saunders, M.L. and D.S. Hunsinger, 2008. Encouraging students to choose a computer-related major: The influence of guidance counselors. Inf. Syst. Educ. J.

UNESCO, 2003. Science and technology education in the Arab world in the 21st century. UNESCO Int. Sci. Technol. Environ. Educ. Newsletter.

Zweben, S., 2013. Computing degree and enrollment trends. Computing Research Association, Washington. 